\title{
Testing Post Tensioned Slabs with Bonded and Unbonded Tendons
}

\author{
Jasmin Osama Abdelhalim, Ezzeldin Yazeed Sayed-Ahmed \\ The American University in Cairo, Construction Engineering Dept. \\ New Cairo, Cairo, Egypt. \\ jasminosama@aucegypt.edu ; eysahmed@aucegypt.edu
}

\begin{abstract}
Post-tensioned slabs are tested in order to investigate the tendon stress at ultimate limit state in case of using bonded and unbonded tendons. The main objective is to compare the values of the mentioned tendon stress to those predicted by ACI 318-19 based on empirical equations for unbonded tendons and based on strain compatibility for bonded ones. The experimental program will be carried on six one-way slabs in four-point flexural loading. Details of the tested slabs and the test set up are presented in this paper. The results of the test carried showed an excellent correlation where almost all of the slabs experimental test results were equal to the theoretical results with a very minor difference around 10 percent.
\end{abstract}

Keywords: bonded tendons, prestressed concrete, post tensioned, unbonded tendons.

\section{Introduction}

Prestressed concrete has various advantages in comparison to traditional reinforced concrete. Prestressing technique increases the tensile and flexural capacity of the concrete elements in addition to preserving the sustainability concept through the reduction in the usage of materials and sequentially the embodied energy [1-3]. Prestressed concrete elements can be either post- or pre-tensioned: tendons of pre-tensioned elements are stressed before the concrete casting, while in posttensioned ones, they are stressed after pouring and hardening of concrete. Two types of tendons are used for post-tensioning concrete elements: bonded and unbonded tendons. Bonded tendons (Figure 1) are seven-wires strands inserted inside a plastic or steel duct, and after stressing the strands, grout is injected to fill the duct. Unbonded tendons (Figure 1) are made up of greased seven-wires strands covered with plastic sheathing [2]. Unbonded tendons have many advantages compared to bonded ones such as better corrosion resistance, ease of construction, flexibility and faster construction rate [4].

The major difference between the two types of tendons is the way of stress transfer from the tendon to the concrete, which makes the bonded tendons more widely acceptable in the Egyptian market than the unbonded tendons.
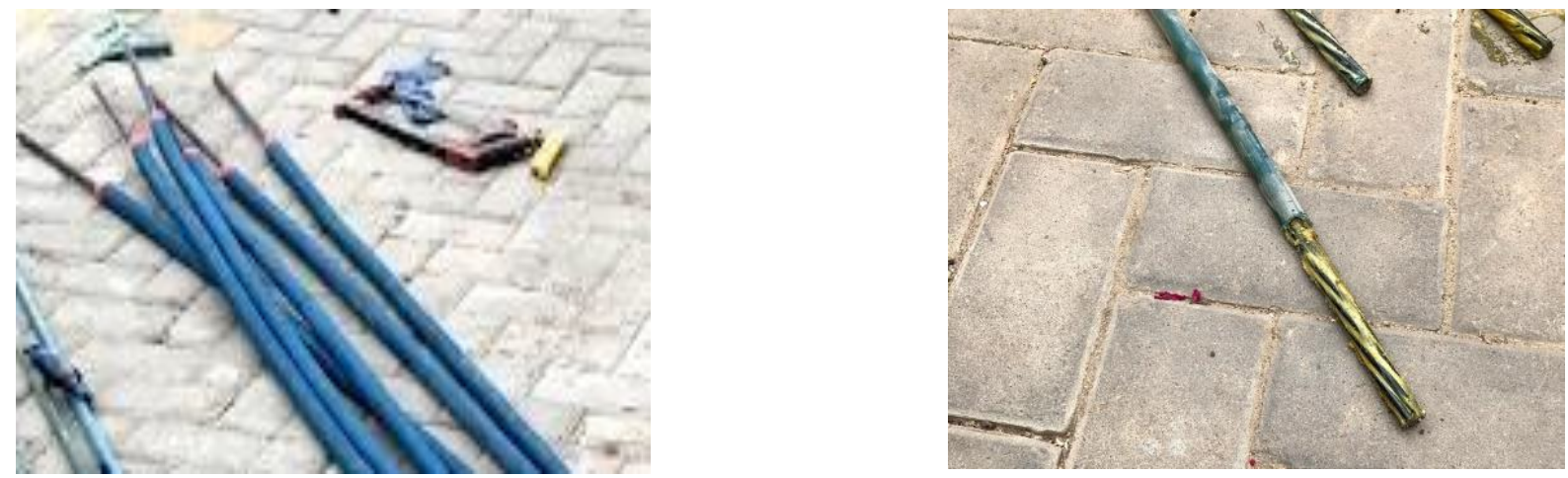

Figure 1. Bonded tendons (left) inserted in corrugated ducts and greased unbonded tendons (right) covered with plastic sheathing.

The stress is transferred from the bonded tendon to the concrete via the bond formed due to grouting. Thus, the stress in the tendons can be calculated by the application of the strain compatibility concept. On the other hand, there is no bond between the unbonded tendons and the surrounding concrete due to the presence of the grease and the plastic sheathing [5]. 
So, empirical equations are adopted by ACI 318-19 [6] provisions to calculate the stress in the unbonded tendons at the ultimate limit state which are given by

$$
\begin{aligned}
& f_{p s}=\text { least of }\left\{\begin{array}{c}
f_{p e}+\left(10,000+f_{c}^{\prime} / 1000 \rho_{p s}\right) \\
f_{p e}+420 \\
f_{p y}
\end{array} \quad \text { span-to-depth } \leq 35\right. \\
& f_{p s}=\text { least of }\left\{\begin{array}{c}
f_{p e}+\left(10,000+f_{c}^{\prime} / 300 \rho p s\right) \\
f_{p e}+210 \\
f_{p y}
\end{array} \quad \text { span-to-depth }>35\right.
\end{aligned}
$$

Where, $f_{p s}$ is the nominal flexural strength of the unbonded tendon, $f_{p e}$ is the effective prestress of the unbonded tendons, $f_{p y}$ is the yield stress of the tendon, $f^{\prime}{ }_{c}$ is the concrete compressive strength, $\rho_{p s}$ is the ratio of the prestressing tendons cross sectional area to the area of concrete section $\left[\mathrm{A}_{\mathrm{ps}} / \mathrm{bd}\right], \mathrm{b}$ is the width of the concrete cross section, and $\mathrm{d}_{\mathrm{p}}$ is the effective depth of the prestressing tendons.

There is no provision in this code that requires the usage of non-prestressing bonding reinforcement for the bonded systems but a minimum requirement for bonding reinforcement is required for the unbonded system for crack control. The minimum non-prestressed reinforcement is added to the prestressed members with unbonded tendons to provide a flexural behaviour at the ultimate strength rather than the tied arch behaviour. The provided reinforcement limits the crack width and spacing at the service load state when the tensile stresses acting on the prestressed concrete element surpass the concrete modulus of rupture.

According to the ACI 318-19 [6] provisions the nominal strength allowed for the bonded tendons is higher than the nominal strength allowed for the unbonded tendons. This gap could be supplemented by the usage of non-prestressed reinforcement, so the bonded tendons are not on favour over the unbonded tendons as the price of the supplementary non-prestressed reinforcement is less than the grouting price [6].

\section{The Experimental Investigation}

\subsection{The Slab Specimens}

The objective of the current research is to investigate the values of the stress in bonded and unbonded tendons at the ultimate limit state and compare these values for unbonded tendons stress to those resulting from the ACI 318-19 [6] equations. An experimental program is designed to test six one-way post-tensioned slabs with bonded and unbonded tendons monotonically to failure under the effect of four-point flexural loading.

The specimens are chosen of slab type because of the lack of previously carried experimental researches on posttensioned slab type specimens and due to the wide usage of these slabs in the construction arena. The six specimens are post-tensioned one-way slabs simply supported with span 4.0 meters, width 1.0 meter and thickness 0.16 meters. They are tested under four-point flexural loading. Three sets, each consists of two slabs, are tested. The first set of slabs contains bonded tendons without non-prestressing reinforcement (BS1 and BS2). The second set of slabs contains unbonded tendons without non-prestressing reinforcement (UBS1 and UBS2). The last set of slabs contains unbonded tendons and non-prestressing reinforcement no.10 $\mathrm{mm} @ 200 \mathrm{~mm}$ in the two orthogonal directions according to the ACI 318-19 [6] requirements (UBSR1 and UBSR2). Each slab contains three $12.7 \mathrm{~mm}$ diameter seven-wire prestressing strands. The six slabs are designed following the ACI 318-19 [6] provisions with the tendons having double harped profiles and shown in Figure 2. End reinforcement (shown as closed stirrups in Figure 2) is added to the six slabs for resisting stresses produced at the local and general anchorage zones and designed according to the ACI 318-19 [6] provisions. Figure 3 shows the six post-tensioned slab specimens forms with all the reinforcement detailing before concrete casting and after the concrete pouring. 
The anchorage system for the bonded slabs is obtained from an Egyptian supplier, Strands-Egypt, while the unbonded anchorage system (Zero void encapsulated system) is imported from GTI-USA. The bonded and the unbonded anchors are shown in Figure 4.
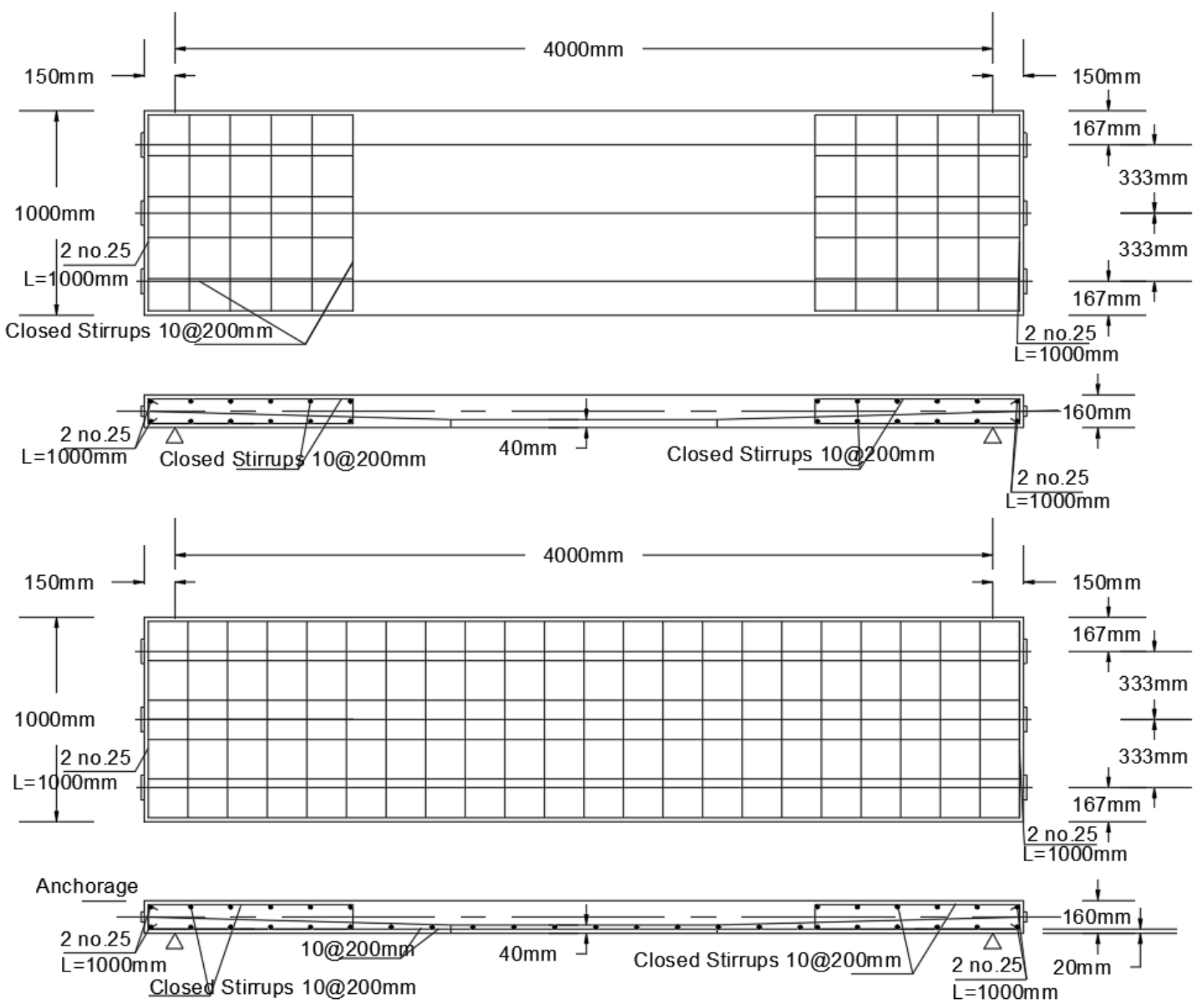

Figure 2. Slab specimen's details for BS1, BS2, UBS1 and UBS2 (above) and UBSR1 and UBSR2 (below). 

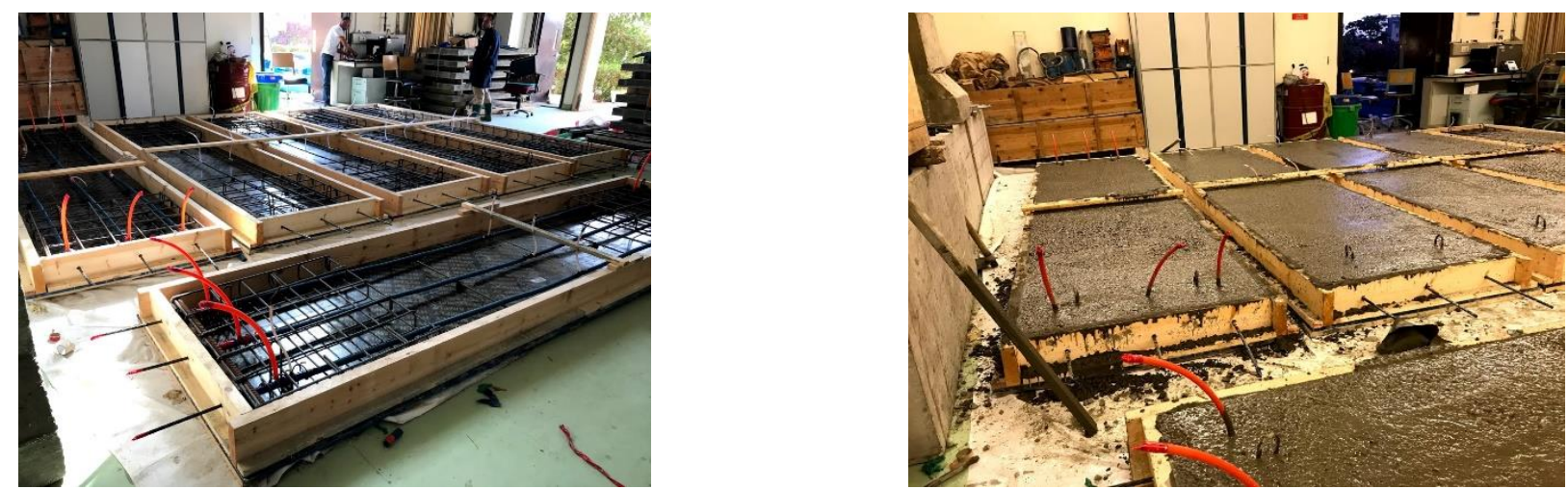

Figure 3. The six post-tensioned slab specimens before concrete casting (left) and after concrete casting (right).

Concrete of compressive strength $30 \mathrm{MPa}$ is intended for the six slab specimens. After the hardening of concrete and reaching compressive strength of average $26.3 \mathrm{MPa}$ after 7 days, the six post-tensioned tendons were stressed: the cubes tested at 7 days of age resulted 23.61, 26.77 and 28.63 MPa.
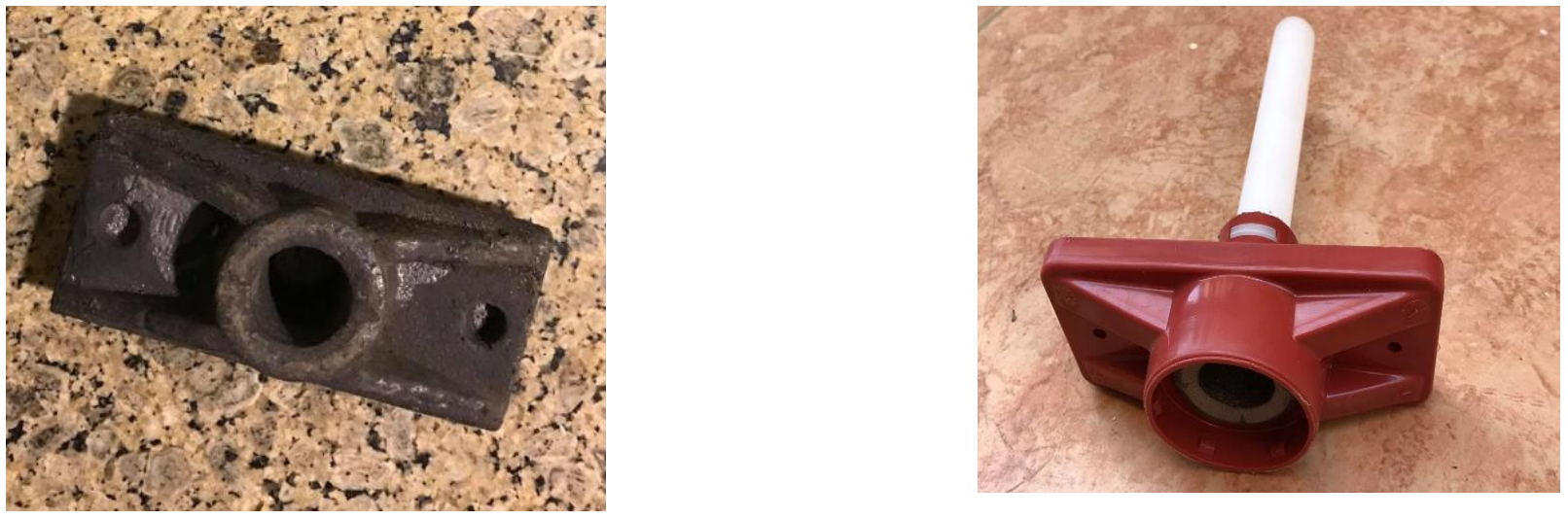

Figure 4. Bonded Egyptian anchor (left) and zero voids encapsulated unboned anchor (right).

The jacking force $P_{j}$ is calculated based on the maximum permissible concrete tensile stresses according to ACI 318-19 [6] provisions which is found to be $459.8 \mathrm{kN}$. Thus, the prestressing force needed for one tendon is around $154 \mathrm{kN}$. Tendons prestressing is sequentially performed. The prestressing was done form the "live" end for the six slabs. Table 1 illustrates the elongation measured for the tendons after the applicaion of the hydraulic jack force.

Table 1 The elongation of the tendons after prestressing in $\mathrm{mm}$

\begin{tabular}{|c|c|c|c|}
\hline Specimen & Tendon no. 1 & Tendon no.2 & Tendon no.3 \\
\hline UBSR1 & 33.5 & 33 & 34 \\
\hline UBSR2 & 33 & 31 & 32 \\
\hline UBS1 & 32.5 & 34 & 36 \\
\hline UBS2 & 34 & 32.5 & 35 \\
\hline BS1 & 43 & 35 & 36 \\
\hline BS2 & 34 & 34 & 35 \\
\hline
\end{tabular}

From the elongation of each tendon the strain is calculated, followed by the calculation of the stress in each tendon that is converted to a jacking force giving the following results; and the equations used are the following: 


$$
\varepsilon_{p e}=\frac{\Delta \mathrm{L}}{\mathrm{L}_{p}} \Rightarrow P_{j}=\left(E_{p} \varepsilon_{p e}\right) A_{p s}
$$

Where, $\varepsilon_{p e}$ is the tendon's strain, $\Delta \mathrm{L}$ is the tendon total shortening, $L_{p}$ the tendon length, $P_{j}$ is the jacking force, $\mathrm{E}$ is the Young's modulus of the tendons steel, and $A_{p s}$ is the tendons cross sectional area. The elongation is obtained from the Table 1, the exact length of the tendon $L_{p}$ is 4.304 meters and the Young's modulus of the prestressing tendons $E_{p}$ is $190,000 \mathrm{MPa}$. Table 2 illustrates the calculation of the jacking force in each tendon.

Table 2 Jacking force calculation in each tendon (Stresses in MPa and the jacking forces are in $\mathrm{kN}$ )

\begin{tabular}{|c|c|c|c|c|c|c|c|c|c|}
\hline Specimen & $\begin{array}{c}\text { Strain, } \\
\text { tendon 1 }\end{array}$ & $\begin{array}{c}\text { Strain, } \\
\text { tendon 2 }\end{array}$ & $\begin{array}{c}\text { Strain, } \\
\text { tendon 3 }\end{array}$ & $\begin{array}{c}\text { Stress, } \\
\text { tendon 1 }\end{array}$ & $\begin{array}{c}\text { Stress, } \\
\text { tendon 2 }\end{array}$ & $\begin{array}{c}\text { Stress, } \\
\text { tendon 3 }\end{array}$ & $\begin{array}{c}\mathrm{P}_{\mathrm{j}} \\
\text { tendon 1 }\end{array}$ & $\begin{array}{c}\mathrm{P}_{\mathrm{j}} \\
\text { tendon 2 }\end{array}$ & $\begin{array}{c}\mathrm{P}_{\mathrm{j}} \\
\text { tendon 3 }\end{array}$ \\
\hline UBSR1 & 0.007783 & 0.007667 & 0.007899 & 1478.8 & 1456.7 & 1500.8 & 145.95 & 143.77 & 148.13 \\
\hline UBSR2 & 0.007667 & 0.007203 & 0.007345 & 1456.7 & 1368.6 & 1395.5 & 143.77 & 135.08 & 137.74 \\
\hline UBS1 & 0.007551 & 0.007899 & 0.008364 & 1434.7 & 1500.8 & 1589.2 & 141.60 & 148.13 & 156.85 \\
\hline UBS2 & 0.007899 & 0.007551 & 0.008132 & 1500.8 & 1434.7 & 1545.1 & 148.12 & 141.60 & 152.5 \\
\hline BS1 & 0.007667 & 0.008132 & 0.008364 & 1456.8 & 1545.1 & 1589.2 & 143.78 & 152.5 & 156.85 \\
\hline BS2 & 0.007899 & 0.007899 & 0.008132 & 1500.8 & 1500.8 & 1545.1 & 148.13 & 148.13 & 152.5 \\
\hline
\end{tabular}

\subsection{Prestress Losses}

The prestressing force losses are calculated according to ACI 318-19 [6] provisions which refers to the Post-Tensioning Institute Manual [3]. The short-term losses are due to elastic shortening, anchorage slippage and friction. While, the longterm losses are due to shrinkage and creep of concrete and relaxation of the tendons. The initial prestressing force (Pi) is thus, the prestressing force after the short-term losses and the effective prestressing force $(\mathrm{Pe})$ is that at the service load stage after all losses. The short-term losses are calculated, starting by the elastic shortening losses, which is given by

$$
\begin{aligned}
& \Delta_{\text {shortening }}=\frac{P_{j} L}{\mathrm{E}_{c} A_{c}} \\
& \Delta \varepsilon_{P-\text { shortening }} \approx \frac{\Delta_{\text {shortening }}}{L_{p}} \quad \text { and } \Delta P_{\text {shortening }}=\frac{2}{3}\left(E_{p} \Delta \varepsilon_{P-\text { shortening }}\right) A_{p}
\end{aligned}
$$

Where, $\Delta_{\text {shortening }}$ is the change in length due to the elastic shortening of the concrete slab, $L$ is the slab span, $E_{c}$ is the modulus of elasticity of the concrete at the initial stage, $A_{c}$ is the cross sectional area of the slab specimen, $P_{j}$ is the jacking force, $\Delta \varepsilon_{\text {shortening }}$ is the change in the tendon strain due to the elastic shortening, $A_{p}$ is the cross sectional area of the tendon and $\Delta P_{\text {shortening }}$ is the prestressing force loss due to elastic shortening which is multiplied by $2 / 3$ to account for the sequential prestressing. Table 3 illustrates the values of the prestressing losses due to elastic shortening. 
Table 3 Values of shortening losses for each tendon

\begin{tabular}{|c|c|c|c|c|c|}
\hline Specimen & $P_{j}(\mathrm{kN})$ & $\begin{array}{c}\Delta_{\text {shortening }} \\
(\mathrm{mm})\end{array}$ & $\Delta \varepsilon_{\text {shortening }}$ & $\begin{array}{c}\Delta f_{p \text {-shortening }} \\
(\mathrm{MPa})\end{array}$ & $\begin{array}{c}\Delta P_{\text {shortening }} \\
(\mathrm{kN})\end{array}$ \\
\hline UBSR1 & 437.86 & 0.57 & 0.000133 & 25.19 & 4.97 \\
\hline UBSR2 & 416.60 & 0.54 & 0.000126 & 23.97 & 4.73 \\
\hline UBS1 & 446.58 & 0.58 & 0.000135 & 25.69 & 5.07 \\
\hline UBS2 & 442.23 & 0.58 & 0.000134 & 25.44 & 5.02 \\
\hline BS1 & 453.13 & 0.59 & 0.000137 & 26.07 & 5.14 \\
\hline BS2 & 448.76 & 0.58 & 0.000136 & 25.82 & 5.09 \\
\hline
\end{tabular}

The losses due to anchorage slippage are neglected since after prestressing the six slabs, it was detected that no slippage occurred for any tendon. The last source of the short-term losses is the friction losses, which occurs due to the wobble effect and the curvature effect of the tendons with empirical coefficients for the wobble and the curvature losses defined by the PTI manual [3] as $k$ and $\mu$, respectively. For the unbonded tendons $\mu$ and $k$ are considered as 0.07 and 0.001 , respectively, while for the bonded tendons they are 0.22 and 0.0075 , respectively. The prestressing losses $\Delta P_{\text {friction }}$ is calculated at the slab mid$\operatorname{span}(x=2.15 \mathrm{~m})$ by

$$
\Delta P_{\text {friction }}=P_{j}\left(1-e^{(\mu \alpha+k x)}\right)
$$

Where $\alpha$ is the angle of tendon curvature in radians. The friction losses due to curvature effect is neglected because the tendon is only inclined by $2^{\circ}$ (the tendon is almost straight). The friction losses are calculated for the six slab and the results are presented in the Table 4.

Table 4 Friction losses values for the six specimens

\begin{tabular}{|c|c|c|c|}
\hline Specimen & $P_{j}(\mathrm{kN})$ & Wobble coefficient $(k)$ & $\Delta P_{\text {friction }}(\mathrm{kN})$ \\
\hline UBSR1 & 437.86 & 0.003 & 2.82 \\
\hline UBSR2 & 416.60 & 0.003 & 2.68 \\
\hline UBS1 & 446.58 & 0.003 & 2.87 \\
\hline UBS2 & 442.23 & 0.003 & 2.84 \\
\hline BS1 & 453.13 & 0.00246 & 2.39 \\
\hline BS2 & 448.76 & 0.00246 & 2.37 \\
\hline
\end{tabular}

The short term losses for each slab specimen are added in kilo newton and calculated as percentage from the jacking force and presented in Table 5

Table 5 Six slab specimen's short term losses values

\begin{tabular}{|c|c|c|c|c|c|c|}
\hline Specimen & $P_{j}(\mathrm{kN})$ & $\Delta P_{\text {shortening }}(\mathrm{kN})$ & $\Delta P_{\text {friction }}(\mathrm{kN})$ & $\Delta P_{j}(\mathrm{kN})$ & $\Delta P_{j} / P_{j} \%$ & $P_{i}(\mathrm{kN})$ \\
\hline UBSR1 & 437.86 & 4.97 & 2.82 & 7.79 & 1.78 & 430.08 \\
\hline UBSR2 & 416.60 & 4.73 & 2.68 & 7.41 & 1.78 & 409.19 \\
\hline UBS1 & 446.58 & 5.07 & 2.87 & 7.94 & 1.78 & 438.64 \\
\hline UBS2 & 442.23 & 5.02 & 2.84 & 7.87 & 1.78 & 434.37 \\
\hline BS1 & 453.13 & 5.14 & 2.39 & 7.54 & 1.66 & 445.60 \\
\hline BS2 & 448.76 & 5.10 & 2.37 & 7.46 & 1.66 & 441.30 \\
\hline
\end{tabular}




\subsection{The Transfer Stage}

In Table 5, the prestressing force at the transfer stage (considering the short term losses is listed as Pi. Based on this value, the compressive and tensile stresses at outer concrete fibres of the slab mid-span section at the transfer stage is calculated and compared to the limitations defined ACI 318-19 [6] provisions. Based on $\mathrm{f}^{\prime}{ }_{\mathrm{ci}}=22 \mathrm{MPa}$, these limits are -13.2 $\mathrm{MPa}$ and $1.17 \mathrm{MPa}$ for the compressive and tensile stress, respectively. The stress at the bottom and top fibres of the midsection of the slabs are calculated and checked versus the ACI318-19 [6] limits; these are listed in Table 6.

Table 6 Top and bottom stresses for the six slab specimens

\begin{tabular}{|c|c|c|c|c|}
\hline Specimen & $\mathrm{f}_{\text {top }}(\mathrm{MPa})$ & $\begin{array}{c}\text { ACI 318-19 [6] limit } \\
(\mathrm{MPa})\end{array}$ & $\mathrm{f}_{\text {bot }}(\mathrm{MPa})$ & $\begin{array}{c}\text { ACI 318-19 [6] limit } \\
(\mathrm{MPa})\end{array}$ \\
\hline UBSR1 & -0.53 & & -4.86 & \\
\cline { 1 - 1 } UBSR2 & -0.60 & & -4.52 & \multirow{2}{*}{-13.20} \\
\hline UBS1 & -0.50 & \multirow{3}{*}{1.17} & -4.98 & \\
\hline UBS2 & -0.52 & & -4.91 \\
\hline BS1 & -0.48 & & -5.09 & \\
\hline BS2 & -0.50 & & -5.02 & \\
\hline
\end{tabular}

\subsection{Instrumentation and Test Set-Up}

Strain gauges are used to measure the change in length at different locations on the concrete and the prestressing tendons. Four strain gauges are fixed on each slab. Three strain gauges are fixed on the slab tendons, while one strain gauge is fixed on the concrete top surface of the slab at the mid-span. Two strain gauges are added on two of the three tendons in each slab at mid-span in order to measure the elongation of the tendons from the start of loading till final failure. The third strain gauge is fixed at the dead end of one of the tendons to detect the long-term losses of the prestressed tendons.

The test setup is designed to test the slab in flexure in a four-point loading fashion. Two line loads are applied on the slabs using two HEB 300 beams, which are supported in the transvers direction of the slab. A third HEB $300,1.60 \mathrm{~m}$ long, is supported on the two HEB 300 parallel to the longitudinal direction of the slab (Figure 5). The length of the 1.60 meters HEB 300 is chosen in order to maintain a trapezoidal bending moment matching the tendon's harped profile. Rubber pads are positioned between the two HEB-300 and the slab specimen. Linear variable differential transducers (LVDTs) are also used to record the deformation of the slab in the mid-span. 


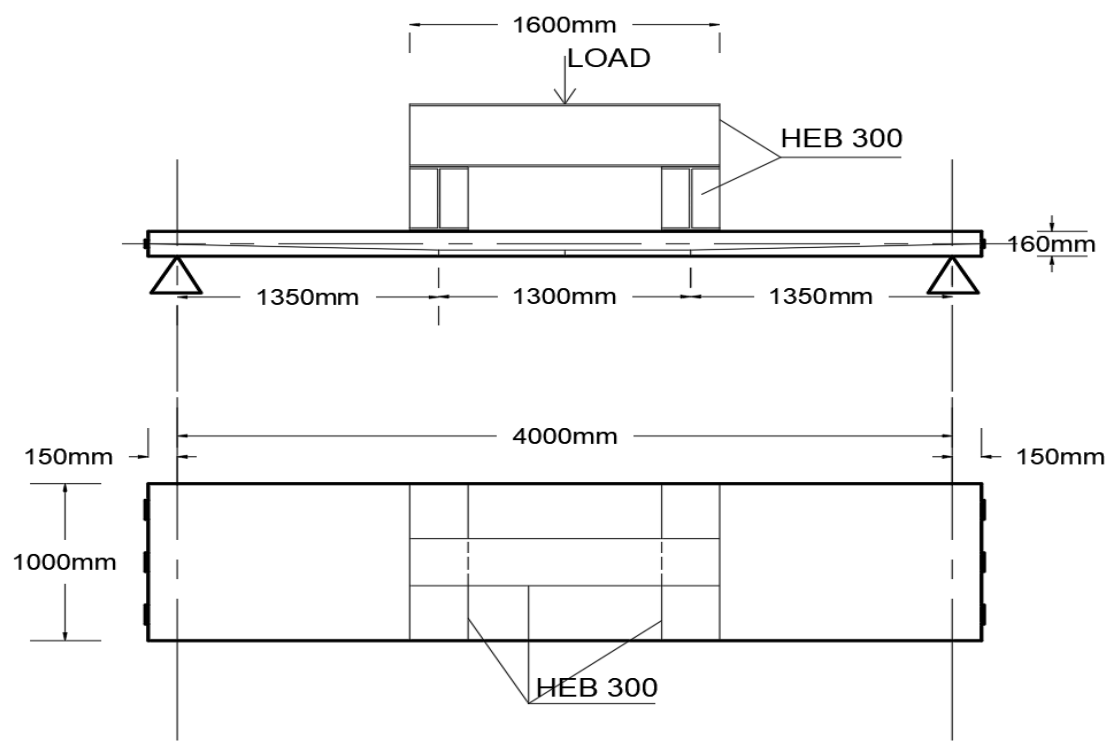

Figure 5. Four point loading testing setup.

\section{Summary}

This paper describes an experimental program designed to test post-tensioned slabs with bonded and unbonded tendons. The slabs are tested in flexure to failure in order to compare the stresses in the bonded and the unbonded tendons to each other and the stresses in the tendons to those calculated based on ACI 318-19 [6] for bonded and unbonded tendons.

The aim of this research is to shed light on the validity of the current equation adopted to calculate the stresses in the unbonded tendons at the ultimate limit state. The experimental work will also scrutinize the reason (if any) of adding additional reinforcement to post tensioned slabs with unbonded tendons. This test has proved its excellent correlation as almost all of the tested slabs have showed a very minor difference between the theoretical and the experimental results. The detailed results of the test and the comparison between the bonded and the unbonded system in addition to the examination of the validity of the ACI 318-19 code equation for calculating the unbonded tendons ultimate stress will be presented elsewhere.

\section{References}

[1] A. A. Abdelrahman, "Applications of Sustainable post-tensioned concrete slabs,” Springer Journal, 2017.

[2] H. Süleymanoğlu, A. Uzel, G. Arslan, "Use of Post-Tensioned Concrete Slabs for Sustainable Design of Buildings," High Tech Concrete: Where Technology and Engineering Meet, Springer, PP 2390-2395, 2018.

[3] PTI, Post-tensioning manual (sixth edition). Phoenix, AZ, 2006.

[4] B. O. Aalami, (1994) "Unbonded and Bonded Post-Tensioning Systems in Building Construction: A Design and Performance Review," Pti Technical Notes.

[5] E. Ellobody, C. Bailey, "Behaviour of Unnonded Post-Tensioned One-way Concrete Slabs," Advances in Structural Engineering, Vol.11, No.1, 2008.

[6] ACI Committee 318. Building Code Requirements for Structural Concrete (ACI 318-2019) and Commentary (ACI 318-2019). American Concrete Institute, 2019.

[7] K. B. Bondy, "Two-Way Post-Tensioned Slabs with Bonded Tendons," PTI Journal, vol.8, no.2, 2012. 